\title{
Mitochondrial metabolism and cancer
}

\author{
Paolo Ettore Porporato ${ }^{1, *}$, Nicoletta Filigheddu, ${ }^{2, *}$, José Manuel Bravo-San Pedro ${ }^{3,4,5,6,7}$, Guido Kroemer, 4, 5, 6, 7, 8, 9 , \\ Lorenzo Galluzzi $i^{3,10,11}$
}

${ }^{I}$ Department of Molecular Biotechnology and Health Sciences, Molecular Biotechnology Center, 10124 Torino, Italy; ${ }^{2}$ Department of Translational Medicine, University of Piemonte Orientale, 28100 Novara, Italy; ${ }^{3}$ Université Paris Descartes/Paris V, Sorbonne Paris Cité, 75006 Paris, France; ${ }^{4}$ Université Pierre et Marie Curie/Paris VI, 75006 Paris, France; ${ }^{5}$ Equipe 11 labellisée par la Ligue contre le Cancer, Centre de Recherche des Cordeliers, 75006 Paris, France; ${ }^{6} I N S E R M$, U1138, 75006 Paris, France; ${ }^{7}$ Metabolomics and Cell Biology Platforms, Gustave Roussy Comprehensive Cancer Institute, 94805 Villejuif, France; ${ }^{8}$ Pôle de Biologie, Hopitâl Européen George Pompidou, AP-HP, 75015 Paris, France; ${ }^{9}$ Department of Women's and Children's Health, Karolinska University Hospital, 17176 Stockholm, Sweden; ${ }^{10}$ Department of Radiation Oncology, Weill Cornell Medical College, New York, NY 10065, USA; ${ }^{11}$ Sandra and Edward Meyer Cancer Center, New York, NY 10065, USA

Glycolysis has long been considered as the major metabolic process for energy production and anabolic growth in cancer cells. Although such a view has been instrumental for the development of powerful imaging tools that are still used in the clinics, it is now clear that mitochondria play a key role in oncogenesis. Besides exerting central bioenergetic functions, mitochondria provide indeed building blocks for tumor anabolism, control redox and calcium homeostasis, participate in transcriptional regulation, and govern cell death. Thus, mitochondria constitute promising targets for the development of novel anticancer agents. However, tumors arise, progress, and respond to therapy in the context of an intimate crosstalk with the host immune system, and many immunological functions rely on intact mitochondrial metabolism. Here, we review the cancer cell-intrinsic and cell-extrinsic mechanisms through which mitochondria influence all steps of oncogenesis, with a focus on the therapeutic potential of targeting mitochondrial metabolism for cancer therapy.

Keywords: autophagy; danger signaling; immunometabolism; oncometabolites; oxidative phosphorylation; mitophagy Cell Research (2018) 28:265-280. doi:10.1038/cr.2017.155; published online 8 December 2017

\section{Introduction}

With the advent of the twenty-first century, two major misconceptions about cancer have eventually been erad-

\footnotetext{
*These two authors contributed equally to this work. Correspondence: Guido Kroemer ${ }^{\mathrm{a}}$, Lorenzo Galluzzi ${ }^{\mathrm{b}}$

${ }^{a}$ E-mail: kroemer@orange.fr

${ }^{\mathrm{b}}$ E-mail: deadoc@vodafone.it

Abbreviations: ${ }^{18} \mathrm{~F}$-FDG (2-[ $\left.{ }^{18} \mathrm{~F}\right]$ fluoro-2-deoxy-D-glucose); 2-HG (2-hydroxyglutarate); $\alpha$-KG ( $\alpha$-ketoglutarate); $\Delta \psi_{\mathrm{m}}$ (mitochondrial transmembrane potential); CSC (cancer stem cell); CTL (cytotoxic T lymphocyte); DC (dendritic cell); EMT (epithelial-to-mesenchymal transition); ETC (electron transport chain); FA (Fanconi anemia); MOMP (mitochondrial outer membrane permeabilization); MPT (mitochondrial permeability transition); mtDNA (mitochondrial DNA); NK (natural killer); OXPHOS (oxidative phosphorylation); PDAC (pancreatic duct adenocarcinoma); PET (positron emission tomography); PPP (pentose phosphate pathway); RCD (regulated cell death); ROS (reactive oxygen species); TAF (tumor-associated fibroblast); TCA (tricarboxylic acid)
}

icated: (1) the notion that cancer is a purely cell-intrinsic disorder that stems from epigenetic or genetic alterations $[1,2]$; and (2) the view that malignant cells satisfy their bioenergetic and anabolic needs mostly (if not only) via aerobic glycolysis [3, 4]. Thus, it is now widely accepted that tumors form, develop and respond to therapy in the context of a complex, bidirectional interaction with the host immune system [5, 6]. Similarly, the fundamental influence of mitochondrial metabolism on all steps of oncogenesis, i.e., malignant transformation, tumor progression and response to treatment, has eventually been given proper recognition $[7,8]$.

Interestingly, the roots of these long-standing misconceptions reside in two notions that de facto revolutionized (in the positive sense of the term) modern medicine: (1) the "self/non-self" dichotomy, as originally theorized by the Australian virologist Sir Frank Macfarlane Burnet (1899-1985) in 1949, proposing that the immune system can only recognize foreign entities $[9,10]$; and (2) the 
so-called "Warburg effect", referring to the elevated uptake of glucose that characterizes a majority of cancers, first described by the German physiologist Otto Heinrich Warburg (1883-1970) in 1927 [11, 12]. The self/nonself theory generated a robust theoretical framework that turned out to be essential for our current understanding of immune responses against invading pathogens [9], while the Warburg effect provided the rationale for the development of an imaging tool that has been (and still is) extensively used in the clinics for the detection and monitoring of neoplasms, 2-[ $\left.{ }^{18} \mathrm{~F}\right]$ fluoro-2-deoxy-D-glucose $\left({ }^{18} \mathrm{~F}-\mathrm{FDG}\right)$ positron emission tomography (PET) [11].

Despite limited experimental support [12, 13], Warburg himself suggested that the ability of malignant cells to maintain elevated glycolytic rates in spite of normal oxygen tension would derive from primary mitochondrial defects [14], an incorrect assumption that de facto relegated mitochondria to a role of mere bystanders of the oncogenic process for decades. Renovated interest in the role of mitochondria in cancer came in the mid-1990s with the demonstration that mitochondrial outer membrane permeabilization (MOMP) constitutes a decisive step in the execution of regulated cell death (RCD) [1518]. This discovery drove an intense wave of investigation that - only a few years later - culminated with the recognition that most (if not all) cancer cells display an accrued resistance to RCD often owing to alterations in the mitochondrial control of the process [19]. As a consequence, considerable efforts were focused on the development of molecules that would target mitochondria as a strategy for chemo- or radio-sensitization [20], and some of these agents are nowadays used in the clinics (e.g., venetoclax, which is currently approved for use in patients with chronic lymphocytic leukemia) [21]. Alongside, mitochondria attracted renovated attention from a metabolic perspective, in particular as it became clear that: (1) some mitochondrial metabolites are sufficient to drive oncogenesis [22], and (2) some mitochondrial circuitries can adapt to serve bioenergetic or anabolic functions, hence endowing malignant cells with considerable metabolic plasticity [23, 24]. Thus, mitochondrial metabolism now stands out as a promising target for the development of novel antineoplastic agents, and several venues are currently being explored in this sense $[25$, 26].

One of the main problems with targeting mitochondria as a strategy to kill malignant cells or sensitize them to treatment is that multiple immune effector cells, and in particular $\mathrm{CD}^{+}$cytotoxic $\mathrm{T}$ lymphocytes (CTLs, which are involved in the efficacy of many - if not all - therapies), display remarkable metabolic similarities to cancer cells $[26,27]$. This calls for the development of refined therapeutic approaches whereby malignant cells are selectively targeted while immune cells are spared from (or rendered insensitive to) the detrimental effects of treatment. Here, we critically review the cancer cell-intrinsic and cell-extrinsic mechanisms whereby mitochondria influence malignant transformation, tumor progression and response to treatment, as we discuss the potential of targeting mitochondrial metabolism for cancer therapy.

\section{Mitochondrial metabolism in malignant transfor- mation}

The term "malignant transformation" generally refers to the conversion of a normal cell into a neoplastic precursor that - in the context of failing immunosurveillance - acquires additional alterations enabling unrestricted proliferative potential, dissemination, and formation of distant macrometastases (cumulatively referred to as "tumor progression") [28]. Importantly, only carcinogen- and transgene-driven models of oncogenesis can recapitulate (albeit with several limitations) malignant transformation. Conversely, widely employed transplantable models including transformed cells of human or rodent origin de facto recapitulate late tumor progression only (as they were derived from primary or metastatic lesions that evaded immunosurveillance) [29]. Mitochondria may contribute to malignant transformation by at least three major mechanisms: (1) mitochondrial reactive oxygen species (ROS) favor the accumulation of potentially oncogenic DNA defects and the activation of potentially oncogenic signaling pathways [30]; (2) the abnormal accumulation of specific mitochondrial metabolites, including fumarate, succinate, and 2-hydroxyglutarate $(2-\mathrm{HG})$, has prominent transforming effects (at least in some models) [31]; (3) functional deficits in MOMP or mitochondrial permeability transition (MPT) are generally required for the survival of neo-formed malignant precursors, which would otherwise succumb to RCD [32, 33].

ROS are established genotoxins [30], and their requirement for malignant transformation is well exemplified by the fact that $\operatorname{Tr} p 53^{-/-}$mice maintained in relatively hypoxic conditions $\left(10 \% \mathrm{O}_{2}\right)$ exhibit a considerable survival advantage secondary to markedly reduced level of tumorigenesis as compared to $\operatorname{Trp} 53^{-/-}$mice maintained in standard atmospheric conditions $\left(21 \% \mathrm{O}_{2}\right)$ [34]. Along similar lines, hypoxia inhibits spontaneous intestinal carcinogenesis in $\mathrm{Apc}^{\mathrm{Min} / \mathrm{+}}$ mice as well as carcinogen-driven oncogenesis in wild-type BALB/c mice [34]. Moreover, mitochondrial DNA (mtDNA) mutations that mildly (but not severely) affect various components of 
the electron transport chain (ETC) as they promote ROS generation have been documented in a variety of tumors $[8,35]$. One of the major mechanisms that control mitochondrial fitness (and hence limit ROS production) is the autophagic removal of damaged mitochondria (commonly known as mitophagy) [36]. In line with this notion, the knockdown or knockout of genes that are essential for autophagy (such as Atg5 or Atg7) can promote oncogenesis in specific contexts [37-39]. Moreover, Fanconi anemia (FA) genes - which are mutated or silenced in a large proportion of human tumors - have recently been shown to be involved in mitophagy [40], suggesting that (at least part of) the oncosuppressive activity of FA proteins may stem from the proficient removal of damaged mitochondria overproducing ROS. Besides favoring mutagenesis, ROS trigger potentially oncogenic signal transduction cascades including mitogen-activated protein kinase (MAPK) [28] and epidermal growth factor receptor (EGFR) signaling [41].

Succinate dehydrogenase complex iron sulfur subunit B (SDHB), fumarate hydratase $(\mathrm{FH})$, isocitrate dehydrogenase (NADP $(+))$ 1, cytosolic (IDH1) and isocitrate dehydrogenase $(\mathrm{NADP}(+))$ 2, mitochondrial $(\mathrm{IDH} 2)$ are affected by germline or somatic mutations in a variety of human tumors [31]. While SDHB and FH are generally hit by loss-of-function mutations, accompanied by the accumulation of fumarate and/or succinate, IDH1 and IDH2 frequently display gain-of-function mutations, leading to the synthesis of 2-HG [42]. Fumarate, succinate and 2-HG behave as bona fide oncometabolites, meaning that their accumulation is sufficient to drive malignant transformation (at least in some models) [42]. All these oncometabolites share the capacity to inhibit $\alpha$-ketoglutarate $(\alpha-K G)$-dependent enzymes that control gene expression at the epigenetic level, such as Jumonji domain (JMJ) histone lysine demethylases as well as ten-eleven translocation (TET) dioxygenases [43, 44], resulting in the expression of a potentially oncogenic transcriptional program associated with a block in terminal differentiation [42, 45, 46]. Moreover, 2-HG alters the $\alpha-K G-d e p e n d e n t$ prolyl oxidase activity of egl-9 family hypoxia inducible factor 1 (EGLN1, best known as PHD2) and EGLN2 (best known as PHD1), hence promoting transformation via a mechanism related to hypoxia inducible factor 1 alpha subunit (HIF1A) stabilization or destabilization [44, 47]. Finally, fumarate can also induce a non-enzymatic post-translational protein modification known as "succination", and succination of kelch like ECH-associated protein 1 (KEAP1) activates the oncogenic transcription factor nuclear factor, erythroid derived 2 (NFE2, best known as NRF2) [48]. Interestingly, the accumulation of succinate and fumarate does not always result from primary mitochondrial defects, but can also derive from signals dispatched from oncogenic proteins such as KRAS [49, 50]. Along similar lines, loss of oncosuppressor genes such as $A P C$ appears to favor malignant transformation also by altering mitochondrial functions [51].

Alterations in the susceptibility of mitochondria to undergo MOMP or MPT accompany a vast majority of human tumors, and they are required for malignant precursors to avoid oncogene-driven RCD [32,33]. Perhaps the most striking example of such alterations derives from the overexpression of BCL2 apoptosis regulator (BCL2), a multifunctional cytoprotective protein that localizes to the mitochondrial outer membrane [32]. Malignant transformation (as well as tumor progression, see below) in the hematopoietic system is often associated with the overexpression of BCL2 or other members of the BCL2 protein family, and this increases considerably the resistance of malignant precursors (as well as established cancer cells) to RCD, at least in part owing to an improved bioenergetic metabolism $[52,53]$. In a subset of follicular lymphoma patients, a chromosomal rearrangement involving BCL2 (normally on chromosome 18) and the immunoglobulin heavy chain locus (normally on chromosome 14$)$ - the so-called $t(14 ; 18)$ translocation [54] - can be detected in a vast majority of blasts, suggesting that it constitutes a very early event in oncogenesis. Many oncogenes beyond $B C L 2$ (e.g., MYC, KRAS) drive malignant transformation as they increase the resistance of the mitochondrial pool to MOMP or MPT, in some cases via a mechanism that alters mitochondrial dynamics [55-57]. Besides triggering RCD, oncogene activation can also promote a permanent proliferative arrest known as cellular senescence, generally as a result of increased oxidative stress [58]. Cancer cells can evade such a response, as they activate pyruvate dehydrogenase kinase 1 (PDK1) or inhibit pyruvate dehydrogenase phosphatase catalytic subunit 2 (PDP2), resulting in limited pyruvate utilization by mitochondria and reduced ROS production [59].

Altogether, these observations exemplify the critical influence of mitochondria on malignant transformation (Figure 1).

\section{Mitochondrial metabolism in tumor progression}

Mitochondria are the key for virtually all facets of tumor progression, not only as a major source of ATP, but also due to (1) their ability to provide building blocks for anabolism via anaplerosis, (2) their capacity to produce ROS, and (3) their central position in RCD signaling. In line with this notion, the ability of mtDNA-depleted $\left(\rho^{0}\right)$ 


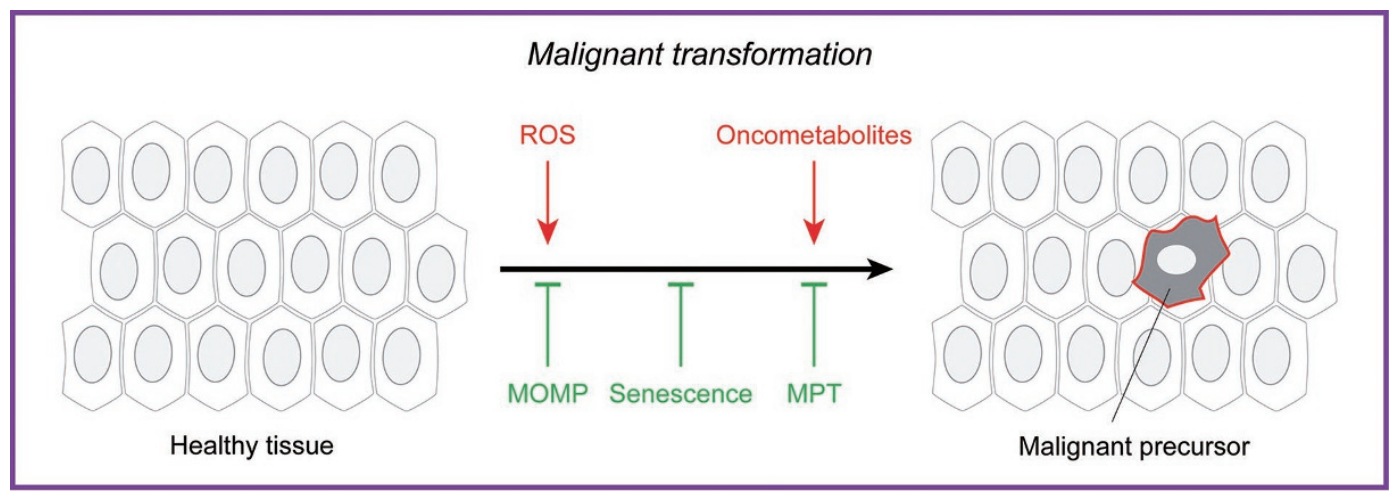

Figure 1 Mitochondrial metabolism in malignant transformation. Mitochondrial dysfunction can promote malignant transformation, i.e., the conversion of a healthy cell into a malignant precursor, as a consequence of (1) reactive oxygen species (ROS) overgeneration, which favors mutagenesis; (2) accumulation of succinate, fumarate or 2-hydroxyglutarate (all of which can operate as oncometabolites, at least in some settings); and/or (3) increased resistance to oncogene-driven mitochondrial outer membrane permeabilization (MOMP)- or mitochondrial permeability transition (MPT)-driven regulated cell death or cellular senescence.

cells to form tumors upon inoculation in immunocompatible hosts is compromised [60-62], but can be recovered (at least in some settings) upon horizontal transfer of whole mitochondria from the host $[60,63]$. Along similar lines, severe defects in autophagy or mitophagy - resulting in fully compromised mitochondrial functions have been associated with decreased tumor progression in multiple models of oncogenesis [39, 64-66].

\section{Proliferation}

Although in vitro, under optimal growth conditions (which differ significantly from those encountered in the tumor microenvironment in vivo), cancer cells can obtain sufficient ATP from glycolysis, mitochondria are required for proliferation unless supraphysiological amounts of uridine and pyruvate are exogenously provided [67] to compensate for pyrimidine and aspartate biosynthesis [68, 69]. Progressing tumors display indeed an extensive and highly plastic metabolic rewiring. This involves not only increased uptake of glucose, a fraction of which is redirected to the pentose phosphate pathway (PPP) for nucleic acid synthesis and glutathione reduction [70], but also the ability to process glutamine oxidatively (for energy production via the Krebs cycle and the ETC) or reductively (for fatty acid synthesis, cholesterol synthesis and the maintenance of oxidative homeostasis via NADPH production) [71-74], the ability to flexibly use various other carbon sources including (but perhaps not limited to) acetate, lactate, serine and glycine as needed [75-79], and the ability to interchangeably use glycolysis, oxidative phosphorylation (OXPHOS) and fatty acid oxidation as the source of energy in response to fluctuating micro- environmental conditions (such as local acidosis, which inhibits glycolysis) [80].

The reversibility of many reactions of the tricarboxylic acid (TCA) cycle and the existence of multiple anaplerotic circuitries centered on mitochondria ensure such a metabolic adaptation $[25,81]$. One key TCA intermediate in this respect is citrate, because it resides at a crucial intersection between catabolic and anabolic metabolism, and hence operates as a major node of flexibility [82]. Besides fueling the oxidative mode of the TCA, citrate can also be converted into acetyl-CoA for export to the cytoplasm and nucleus $[4,81]$, where it can either be employed for fatty acid and cholesterol synthesis (to support the membrane need associated with intense proliferation) or used for acetylation reactions, which regulate transcription as well as cytoplasmic processes including autophagy $[36,83,84]$. In line with this notion, the enzyme that converts citrate into acetyl-CoA, i.e., ATP citrate lyase (ACLY), is required for cancer cells to proliferate at optimal rates [85], but not for normal cells to do so (owing to a glucose-to-acetate metabolic switch) [86]. Reductive glutamine metabolism is the major source of citrate in the presence of mitochondrial defects, as well as under hypoxic conditions (as a function of the $\alpha-\mathrm{KG} /$ citrate ratio) $[23,73,87]$. In this latter scenario, serine catabolism via serine hydroxymethyltransferase 2 (SHMT2) provides reducing equivalents to sustain NADPH production (which is critical for lipid synthesis and the preservation of redox homeostasis) $[79,88]$. Cytosolic malic enzyme 1 (ME1) mediates a similar function in pancreatic duct adenocarcinomas (PDACs) and highly proliferating breast cancers, ensuring the synthesis of NADPH from 
glutamate [72, 89]. Interestingly, mitochondrial ME2 is deleted in a fraction of human PDACs, which renders them dependent on ME3-driven NADPH synthesis for survival and proliferation [90].

Acetyl-CoA-derived acetoacetate also supports cancer proliferation by boosting BRAF kinase activity and consequently MAPK signaling [91, 92]. Along similar lines, slightly elevated levels of ROS stimulate proliferation by inactivating tumor suppressors such as phosphatase and tensin homolog (PTEN) or by stabilizing HIF1A [93, 94]. Moreover, physiological ROS levels contribute to the regulation of mitochondrial dynamics [95], which is intimately involved not only in mitochondrial biogenesis, but also in the control of mitochondrial metabolism [96]. In line with this notion, multiple tumors overexpress ATPase inhibitory factor 1 (ATPIF1), which favors the dimerization of ETC complex V to limit ATP production and (as a side effect) increases ROS generation [97, 98]. Intriguingly, ROS-driven cellular senescence can paradoxically support proliferation in a cell-extrinsic manner, as it sustains the secretion of mitogenic factors that act on neighboring cancer cells with intact proliferative capacities $[99,100]$. These observations exemplify the fundamental role of mitochondrial products at the interface of metabolism and signaling.

\section{Resistance to spontaneous $R C D$}

Progressing neoplasms encounter harsh microenvironmental conditions (e.g., hypoxia, low nutrient availability, growth factor withdrawal), which would normally drive mitochondrial RCD via MOMP or MPT $[32,33]$. Malignant cells, however, acquire several alterations that increase the mitochondrial threshold for irreversible permeabilization, beyond the overexpression of BCL2 family members (see above) [101]. Some (but not all) tumors are characterized by an elevated mitochondrial transmembrane potential $\left(\Delta \psi_{\mathrm{m}}\right)$ linked to high glycolytic rates and increased resistance to RCD [102]. In this scenario, restoring pyruvate generation with chemical PDK1 inhibitors appears to be sufficient to cause RCD and inhibit tumor growth in vivo [102]. Similarly, detaching hexokinase 1 (HXK1) or HXK2 - the enzymes that convert glucose into glucose-6-phosphate in the first step of glycolysis - from mitochondria has been proposed to cause MOMP in cancer cells of different origin [103]. Moreover, the increased abundance of reduced glutathione that originates from a proficient reductive metabolism prevents cytochrome $c$, somatic (CYCS) from oxidation, which limits its capacity to activate apoptotic RCD upon MOMP [104]. The maintenance of optimal antioxidant defenses is also fundamental for cancer cells to avoid ROS-driven MPT, and oncogene signaling, glycolysis, as well as reductive glutamine carboxylation play a major role in this sense $[88,105,106]$. Interestingly, such a defense mechanism - which is partially related to the Warburg effect - appears to be conserved in yeast [107]. That said, slightly elevated ROS levels may increase the resistance of cancer cells to RCD by (1) triggering an adaptative hormetic response reminiscent of ischemic preconditioning [108, 109], and/or (2) promoting autophagy activation [110]. Interestingly, the supramolecular entity responsible for MPT, the so-called "permeability transition pore complex" operates in the context of physical and functional interactions with ETC components (notably, complex V) and other constituents of the molecular machinery for mitochondrial ATP synthesis [98]. In several cancer cells, proficient ATP production by mitochondria is associated with optimal $\mathrm{Ca}^{2+}$ homeostasis and limited MPT sensitivity [111]. Mitochondrial dynamics is also involved in the increased resistance of cancer cells to MOMP and MPT. Malignant cells cope with glucose deprivation by shifting to OXPHOS upon mitochondrial elongation secondary to dynamin 1-like (DNM1L) inhibition [112], which is important to generate an efficient mitochondrial network upon the mitophagic removal of dysfunctional components [113]. Taken together, these observations suggest the existence of an intimate and bidirectional link between metabolism and mitochondrial RCD control.

\section{Diversification and interaction with the stroma}

Progressing malignancies acquire a high degree of phenotypic and metabolic plasticity as they establish functional interactions with non-transformed components of the tumor microenvironment [114-116]. Both these aspects of the biology of malignant cells have been largely overlooked by studies based on cultured cancer cell lines. Recent in vivo work revealed that not only the oncogenic driver, but also the tumor microenvironment (in particular tissue of origin) influence the metabolic profile of malignant cells [117-119].

One of the (hitherto debated) models of tumor evolution proposes the existence of a cancer stem cell (CSC) population endowed with self-renewing ability and responsible for both local progression and recurrence [120]. As compared to their more differentiated counterparts, CSCs from multiple malignancies including osteosarcoma, glioblastoma, and breast cancer display a predominantly glycolytic metabolism [121-123]. However, CSCs from other tumors such as ovarian cancer appear to primarily rely on OXPHOS for ATP synthesis [124]. Interestingly, different subsets of CSCs from the same tumor have been reported to preferentially catabolize glucose in a disparate manner $[125,126]$, suggesting that 
an additional layer of heterogeneity may exist within the CSC compartment to favor metabolic plasticity [127, 128]. That said, the study of CSCs is complicated by the lack of widely accepted surface biomarkers for isolation, as well as by the tendency of these cells to rapidly evolve in culture. This implies that additional investigation is required to elucidate the precise metabolic profile of CSCs from different tumors and whether mitochondrial metabolism may offer targets for therapeutic interventions in this setting.

Prostate cancer cells reprogram tumor-associated fibroblasts (TAFs) toward anaerobic glycolysis, resulting in lactate secretion in the microenvironment and lactate-driven oxidative metabolism in malignant cells [129]. Along similar lines, PDAC cells drive TAFs into autophagic responses that ultimately sustain tumor growth by increasing the local availability of alanine (employed by cancer cells as a carbon source) [130]. Extracellular proteins can also be utilized by PDAC cells for carbon supply upon macropinocytosis [131], but thus far no mechanisms whereby cancer cells stimulate protein secretion by non-transformed components of the tumor microenvironment for nutritional purposes have been described. Along similar lines, prostate, ovarian, breast, and colorectal cancer cells have been shown to obtain fatty acids for oxidative metabolism from local adipocytes, providing a support to tumor progression [132-135]. These observations exemplify parasitism-like relationships established by malignant cells in the tumor microenvironment. In addition, cancer cells can engage in metabolic competition for nutrients at limited availability, such as glucose and tryptophan, with immune effector cells (which reflects the metabolic similarities between highly proliferating cells) [136-138]. Such a competition is expected to influence the likelihood of natural immunosurveillance to control tumor progression. Finally, cancer cells from different regions of the tumor have been proposed to engage in a metabolic symbiosis involving the transfer of glycolysis-derived lactate from hypoxic to normoxic areas, where it would be employed to fuel OXPHOS (as a strategy to avoid competition for glucose) [139, 140]. Additional investigation is required to elucidate the actual pathophysiological relevance of this process in human malignancies.

\section{Metastatic dissemination}

The term metastatic dissemination (also known as metastatic cascade) generally refers to a multi-step process whereby cancer cells acquire the ability to colonize and form macroscopic lesions at distant sites [141]. Although macrometastases are generally considered as glycolytic entities (because they are often detectable by ${ }^{18} \mathrm{~F}$-FDG
PET), this is not always the case [142]. One of the first alterations of the metastatic cascade is the so-called epithelial-to-mesenchymal transition (EMT), which endows malignant cells with increased invasive potential [143]. Several mitochondrial metabolites favor the EMT [144], in particular fumarate (owing to its ability to repress the transcription of the antimetastatic microRNAs upon inhibition of TET dioxygenases) [145]. Optimal mitochondrial biogenesis and OXPHOS seem also to be required for metastatic dissemination, as demonstrated upon silencing of the master regulator PPARG coactivator 1 alpha (PPARGC1A, best known as PGC-1 $\alpha$ ) in models of breast cancer [146], and upon silencing of family with sequence similarity 210 member B (FAM210B) in models of ovarian cancer (resulting in PDK4 downregulation and consequent utilization of glycolytic pyruvate in the TCA cycle) [147]. Moreover, local invasion relies (at least in part) on oxidative mitochondrial metabolism at the cellular leading edge, resulting in cytoskeletal alterations required for motility [148-150]. Mitophagic defects also promote metastatic dissemination [151], most likely by favoring mild ROS overproduction [152-154]. ROS indeed activate several signal transduction cascades associated with metastatic dissemination, including SRC and protein tyrosine kinase 2 beta (PTK2B) signaling $[153,155]$. In line with this notion, a genetic signature of mitochondrial dysfunction has been associated with metastatic dissemination and dismal prognosis in patients affected by nine different tumors [156]. Of note, imbalances in mitochondrial dynamics have also been linked with mild ROS overproduction and consequent metastatic dissemination [157, 158]. Conversely, in the presence of severe oxidative stress, ROS de facto inhibit metastatic dissemination, most likely as a direct consequence of reduced fitness and RCD or cellular senescence [159-161]. In summary, although established macrometastases are generally characterized by elevated glucose uptake (presumably reflecting an intense glycolytic metabolism that boosts antioxidant defenses) [107], OXPHOS and consequent ROS generation (provided that it remains below a cytotoxic threshold) are required for previous steps of the metastatic cascade. Most likely, there is a considerable heterogeneity in the extent to which metastatic lesions of different origin [117] or at different anatomical locations [162] actually rely on glycolytic versus respiratory metabolism. Further investigation is required to shed light on all the factors that influence the metabolic profile of macrometastatic lesions.

Altogether, these considerations suggest that mitochondria reside at a preferential hub connecting metabolism and signaling that is fundamental for tumor progression (Figure 2) 


\section{Mitochondrial metabolism and therapeutic responses}

The ultimate objective of conventional chemotherapeutics, targeted anticancer agents, radiation therapy as well as immunotherapy is to elicit the death or permanent inactivation (via cellular senescence or terminal differentiation) of malignant cells (directly and/or as a consequence of immunological mechanisms) [6]. Mitochondria are critically involved in the control of RCD triggered by all these treatments, implying that alterations of the propensity of mitochondria to undergo MOMP or MPT underlie a majority of cases of primary and acquired resistance [163-166]. As mentioned above, this notion drove an intensive wave of research aimed at the identification of molecules that would kill transformed cells or sensitize them to treatment by priming MOMP or MPT, such as the FDA-approved agent venetoclax [21]. Discussing the regulation of apoptotic and necrotic RCD by mitochondria in details goes beyond the scope of the present review $[167,168]$. That said, however, it should be noted that (1) RCD regulation at mitochondria involves a robust metabolic (rather than purely structural) component; (2) several metabolic aspects of the mitochondrial biology also influence therapeutic responses [101, 169] and (3) metabolic enzymes residing within mitochondria such as mutant IDH2 are being harnessed for the development of anticancer agents promoting terminal differentiation $[45$,
170, 171].

$\mathrm{BRAF}^{\mathrm{V} 600 \mathrm{E}}$ inhibition with the FDA-approved agent vemurafenib is associated with a switch from glycolysis to OXPHOS, which is required for melanoma cells to resist treatment [172]. In this model, the ETC inhibitor honokiol is sufficient to abrogate resistance and restore cancer cell killing by vemurafenib [172]. Oncogene ablation in $\mathrm{KRAS}^{\mathrm{G} 12 \mathrm{D}}$-driven PDAC cells results in the selection of a subpopulation of cells predominantly relying on OXPHOS for energy production [173]. A similar switch from glycolysis to OXPHOS has also been documented upon MYC/KRAS or MYC/ERBB2 ablation in breast cancer cells [174], and in the context of acquired resistance to phosphoinositide-3-kinase (PI3K) inhibition in glioma cells [175]. Moreover, resistance to PI3K inhibition in breast cancer cells has been linked to a switch from glucose to lactate as a main source of carbon units [176]. The activity of various transporters of the ATP-binding cassette (ABC) family - which support chemoresistance as they export a wide spectrum of xenobiotics - depends on OXPHOS-derived ATP availability [177]. In some cases, the expression of ABC transporters and the consequent acquisition of a chemoresistant phenotype stems from OXPHOS-driven inflammatory reactions culminating in the secretion of interleukin 6 (IL6) and tumor necrosis factor (TNF) into the tumor microenvironment [178]. Thus, in cells with a predom-

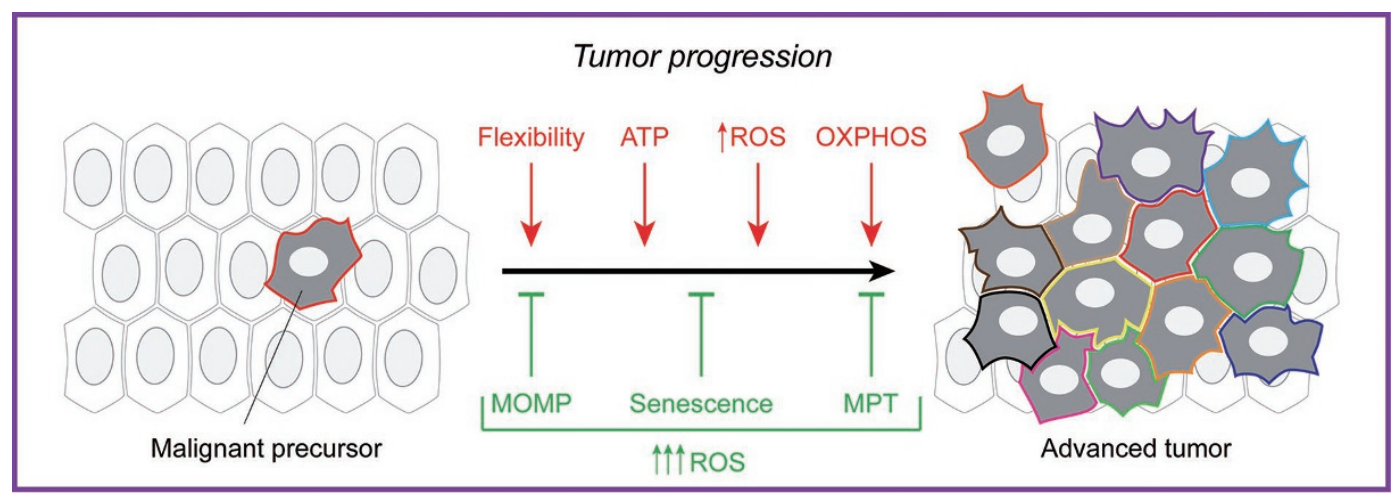

Figure 2 Mitochondrial metabolism in tumor progression. Mitochondria influence multiple processes that underpin tumor progression, including the proliferation of transformed cells, their resistance to adverse microenvironmental conditions, their diversification, their interaction with the tumor stroma and their dissemination toward distant anatomical sites. In particular, (1) mitochondria are major sources of ATP and building blocks for the proliferation of malignant cells; (2) progressing cancer cells display an increased threshold for mitochondrial outer membrane permeabilization (MOMP) and mitochondrial permeability transition (MPT), which renders them less sensitive to harsh microenvironmental conditions; (3) slightly supraphysiological levels of mitochondrial reactive oxygen species (ROS) foster tumor diversification (herein represented with assorted plasma membrane colors) by favoring mutagenesis; (4) different subsets of malignant cells exhibit differential metabolic profiles, which are important for their survival and function; (5) the metastatic cascade relies on optimal mitochondrial biogenesis and oxidative phosphorylation (OXPHOS), at least at the initial dissemination step. However, imbalanced ROS overproduction consequent to severe mitochondrial dysfunction is generally incompatible with tumor progression, resulting in MOMP- or MPT-driven regulated cell death or cellular senescence. 
inantly glycolytic metabolism, OXPHOS can promote resistance to treatment via both cancer cell-intrinsic and cell-extrinsic pathways. Conversely, malignant cells that predominantly utilize OXPHOS for energy production, including pancreatic CSCs, can become resistant to ETC inhibition as they acquire a partially glycolytic metabolism depending on MYC expression [179]. Likewise, chemoresistant ovarian cancer cells display a switch from OXPHOS to glycolysis accompanied by a PPP-dependent surge in antioxidant defenses [180]. Taken together, these observations suggest that the ability of most (if not all) cancer cells to flexibly rewire their mitochondrial metabolism underlies multiple instances of chemoresistance. This holds true for antineoplastic agents other than conventional chemotherapy, including radiation therapy [181], antiangiogenic drugs [182-184], and natural killer (NK)-based immunotherapy [185]. In this latter case, OXPHOS supports the resistance of cancer cells to NK cell-mediated lysis as it promotes the expression of MHC class I molecules (potentially resulting in restored sensitivity to CTL-mediated lysis) [185].

Thus, different forms of treatment establish compensatory metabolic networks that support cancer cell survival. Importantly, such metabolic perturbations may provide targets for the development of novel agents that sensitize cancer cells to treatment. Preclinical evidence in support of this notion is accumulating [186]. In summary, besides controlling multiple forms of RCD, mitochondria impact the response of cancer cells to treatment via metabolic rewiring (Figure 3).

\section{Mitochondrial metabolism in immunosurveillance}

Mitochondria influence immunosurveillance via both cancer cell-intrinsic and cancer cell-extrinsic mechanisms. On the one hand, mitochondria are the source of many danger signals released by cancer cells as they die, and these signals are crucial for the activation of dendritic cells (DCs) to optimally prime tumor-targeting immune responses [187]. On the other hand, mitochondrial metabolism is involved in many functions linked to anticancer immunity, including (but not limited to) inflammasome activation, the establishment of protective immunological memory as well as the differentiation and tumoricidal activity of specific macrophage subsets [188, 189].

The best characterized mitochondrial product that participates in the elicitation of immune responses to dying cancer cells is ATP [190]. Extracellular ATP — which dying cancer cells can release in considerable amounts only if they can mount autophagic responses before death [191, 192] - mediates indeed prominent immunostimulatory and chemotactic functions upon binding to purinergic receptor P2X 7 (P2RX7) and purinergic receptor P2Y2 (P2RY2), respectively, on the surface of DCs or their precursors [193-195]. In line with this notion, autophagy-deficient malignant cells lose the ability of driving anticancer immunity as they succumb to chemotherapy or radiation therapy in vivo, a detrimental effect that can be partially corrected by inhibiting extracellular ATP degradation by ectonucleoside triphosphate diphosphohydro-

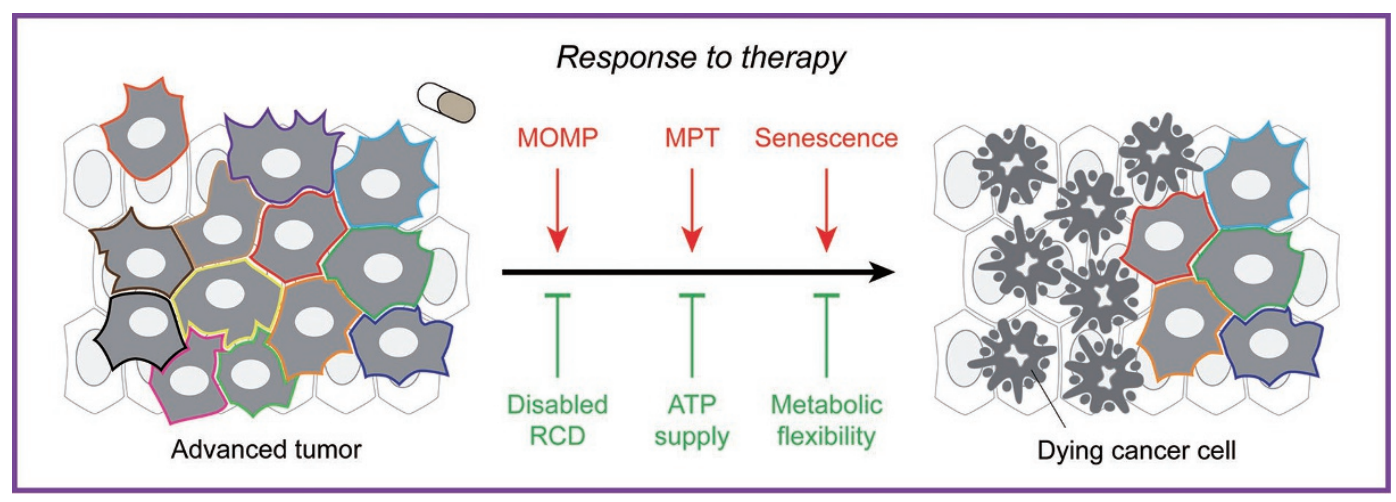

Figure 3 Mitochondrial metabolism in response to treatment. All forms of treatment, including chemotherapy, radiation therapy and immunotherapy, aim at triggering the demise — via regulated cell death (RCD) — or permanent inactivation — via cellular senescence — of malignant cells (directly, or as a consequence of immunological mechanisms). Thus, mitochondria control therapy-driven RCD in cancer cells, implying that alterations in the molecular mechanism underpinning mitochondrial outer membrane permeabilization (MOMP) and mitochondrial permeability transition (MPT) are a major source of resistance. Moreover, mitochondrial ATP fuels several pumps of the ATP-binding cassette family, hence fostering chemoresistance upon the extrusion of xenobiotics from malignant cells. Finally, the ability of malignant cells to flexibly switch between glycolysis and oxidative phosphorylation appears to play a major role in multiple instances of resistance to oncogene inhibition. 


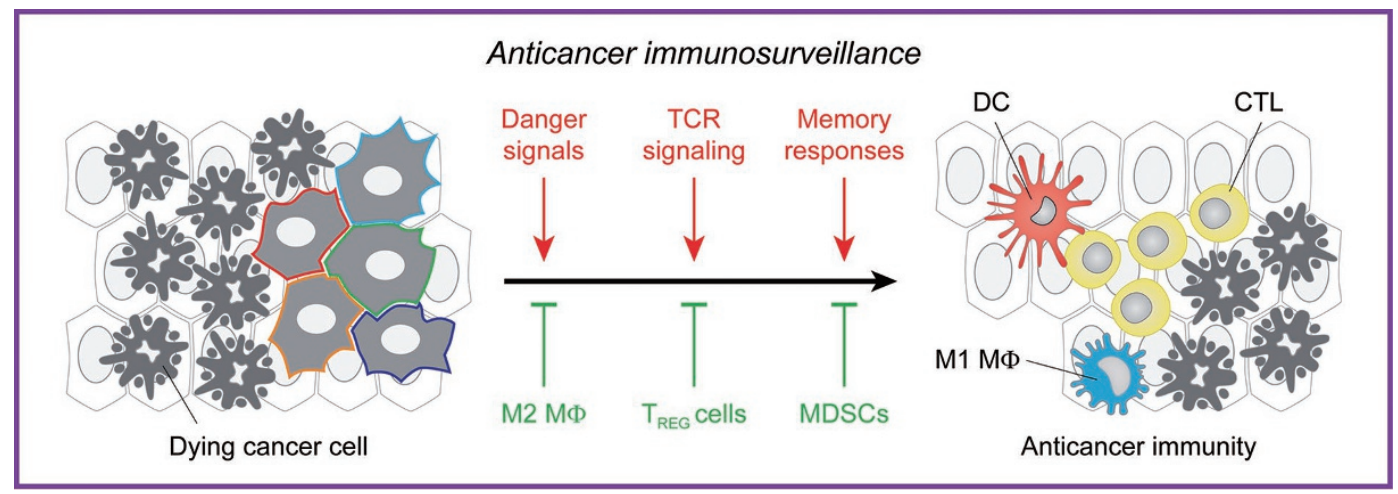

Figure 4 Mitochondrial metabolism in immunosurveillance. Mitochondria are fundamental for the recognition of cancer cells by the immune system, as well as for the consequent activation of a tumor-targeting immune response. On the one hand, mitochondrial products including ATP, reactive oxygen species (ROS) and mitochondrial DNA (mtDNA) operate as danger signals, either extracellularly (like ATP) or intracellularly (like ROS and mtDNA). On the other hand, mitochondrial ROS are required for T-cell activation in response to TCR engagement, and oxidative phosphorylation (OXPHOS) is required for the establishment of immunological memory as well as for the tumoricidal and pro-inflammatory activity of M1 macrophages (MФ). However, OXPHOS also supports the differentiation of immunosuppressive cells including M2 macrophages, $\mathrm{CD} 4^{+} \mathrm{CD} 25^{+} \mathrm{FOXP} 3^{+}$ regulatory $T\left(T_{R E G}\right)$ cells and myeloid-derived suppressor cells (MDSCs). CTL, cytotoxic T lymphocyte.

lase 1 (ENTPD1; best known as CD39) [191, 196, 197]. Moreover, autophagy activation with caloric restriction or molecules that mimic the biochemical effects of starvation boosts the therapeutic efficacy of immunogenic treatment modalities (including anthracycline-based chemotherapy) in rodent tumor models, an effect that is abolished by the depletion of ATG5 or ATG7 as well as by the overexpression of CD39 [196, 198, 199]. Mitochondria contain many other molecules that can operate as extracellular danger signals, including (but not limited to) $\mathrm{N}$-formylated peptides and mtDNA [187]. However, while the relevance of some of these molecules in other disease settings (e.g., systemic inflammatory response syndrome) is well-established [200], their role in anticancer immunity remains to be fully elucidated. Indeed, the receptor for $N$-formylated peptides (which is expressed by DCs) appears to be required for dying cancer cells to elicit a tumor-targeting immune response, but it does so by binding to another danger signal, i.e., annexin A1 (ANXA1) [201]. That said, the release of mtDNA upon MOMP promotes the secretion of type I interferon by malignant cells, and this is required for the activation of optimal anticancer immune responses upon chemotherapy and radiation therapy [202-205]. Thus, mtDNA also operates as an intracellular danger signal to connect intracellular stress responses to the preservation of extracellular homeostasis [206].

CTLs and helper T cells responding to antigenic stimulation engage in a proliferative response that - similar to cancer cell proliferation - extensively relies on glycolysis and is supported by mitochondrial fragmentation
[207-209]. In addition, mitochondrial ROS are required not only for proximal TCR signaling, but also for the activation of multiple transcription factors necessary for optimal T-cell functions, such as NF- $\mathrm{KB}$ and nuclear factor of activated T-cells 1 (NFATC1; best known as NFAT) $[210,211]$. At odds with their effector counterparts, memory $\mathrm{T}$ cells predominantly rely on fatty acid oxidation and OXPHOS to support their metabolic needs, a result of a metabolic reprogramming that involves not only mitochondrial elongation but also mechanistic target of rapamycin complex 1 (MTORC1) inhibition coupled to autophagy activation $[208,212,213]$. Intriguingly, a similar metabolic profile is also displayed by immunosuppressive cell types including $\mathrm{CD} 4^{+} \mathrm{CD} 25^{+} \mathrm{FOXP} 3^{+}$ regulatory $\mathrm{T}$ cells and myeloid-derived suppressor cells $[214,215]$, which presumably renders them less sensitive to metabolic competition for glucose within the tumor microenvironment.

Macrophage polarization and activity are also influenced by mitochondrial metabolism. On the one hand, inhibition of the ETC appears to promote the differentiation of macrophages toward a pro-inflammatory and tumoricidal state (generally referred to as M1), which display a predominantly glycolytic metabolism secondary to the autophagic removal of mitochondria [216-218]. Conversely, M2-polarized macrophages, which generally exert tumor-supporting functions, preferentially employ OXPHOS as a source of ATP, especially in hypoxic conditions $[219,220]$. However, the oxidative burst that underlies the phagocytic activity of M1 macrophages depends on ROS of direct or indirect (via NADPH) mi- 


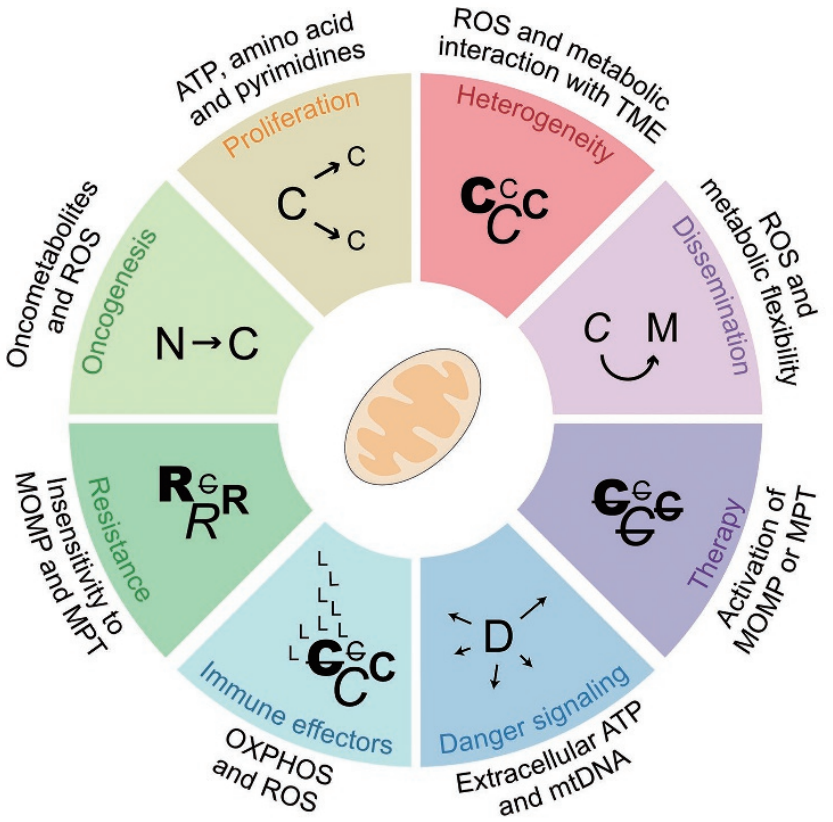

Figure 5 Mitochondrial metabolism and oncogenesis. Mitochondria have a major impact on virtually all processes linked to oncogenesis, encompassing malignant transformation, tumor progression, response to treatment and anticancer immunosurveillance. C, cancer cell; D, dying cancer cell; L, lymphocyte; $M$, metastatic cancer cell; mtDNA, mitochondrial DNA; MOMP, mitochondrial outer membrane permeabilization; MPT, mitochondrial permeability transition; N, normal cell; OXPHOS, oxidative phosphorylation; R, resistant cancer cell; ROS, reactive oxygen species; TME, tumor microenvironment.

tochondrial derivation [221]. A similar consideration applies to the pro-inflammatory activity of M1 macrophages, which relies on ROS-dependent NF- $\kappa B$ transcriptional responses as well as on the activation of the so-called inflammasome, a supramolecular platform that produces IL1 $\beta$ and IL18 in a ROS- and mtDNA-dependent manner [222, 223].

Taken together, these observations exemplify the intricate involvement of mitochondrial metabolism in anticancer immunosurveillance (Figure 4).

\section{Concluding remarks and perspectives}

Mitochondria have attracted considerable attention as targets for the development of novel anticancer agents, not only because they have a central role in the resistance of malignant cells to RCD induction by treatment, but also because they underlie their phenotypic and metabolic plasticity (Figure 5). The case of venetoclax, a molecule that triggers RCD by mimicking the activity of pro-apoptotic members of the BCL2 protein family, well exemplifies the high potential of agents targeting mitochondria for the treatment of specific malignancies [21]. However, non-specifically targeting mitochondrial functions within the tumor microenvironment may have major unwarranted effects including the inhibition of anticancer immune responses, a situation that reminisces the use of pharmacological inhibitors of autophagy [224]. Thus, refined strategies that allow for specifically modulating mitochondrial functions in selected cell populations will have to be devised for the therapeutic potential of mitochondria-targeting agents to be fully harnessed in the clinics. A large body of preclinical and clinical work is still required for this ambitious objective to become a clinical reality.

\section{Acknowledgments}

PEP is supported by Italian Ministry for University and Research (MIUR, Rita Levi-Montalcini program for young researchers, 2014). NF is supported by Fondazione Cariplo (grant 20150634). GK is supported by the French Ligue contre le Cancer (équipe labellisée); Agence National de la Recherche (ANR) -Projets blancs; ANR under the frame of E-Rare-2, the ERA-Net for Research on Rare Diseases; Association pour la recherche sur le cancer (ARC); Cancéropôle Ile-de-France; Institut National du Cancer (INCa); Institut Universitaire de France; Fondation pour la Recherche Médicale (FRM); the European Commission (ArtForce); the European Research Council (ERC); the LeDucq Foundation; the LabEx Immuno-Oncology; the SIRIC Stratified Oncology Cell DNA Repair and Tumor Immune Elimination (SOCRATE); the SIRIC Cancer Research and Personalized Medicine (CARPEM); and the Paris Alliance of Cancer Research Institutes (PACRI). LG is supported by an intramural startup from the Department of Radiation Oncology of Weill Cornell Medical College (New York, USA), and by Sotio a.s. (Prague, Czech Republic).

\section{Competing Financial Interests}

NF is a consultant to Lyric Pharmaceuticals (South San Francisco, CA, USA). LG provides remunerated consulting to OmniSEQ (Buffalo, NY, USA). The remaining authors declare that they have no competing interests.

\section{References}

1 Bui JD, Schreiber RD. Cancer immunosurveillance, immunoediting and inflammation: independent or interdependent processes? Curr Opin Immunol 2007; 19:203-208.

2 Kroemer G, Senovilla L, Galluzzi L, Andre F, Zitvogel L. Natural and therapy-induced immunosurveillance in breast cancer. Nat Med 2015; 21:1128-1138.

3 Erez A, DeBerardinis RJ. Metabolic dysregulation in monogenic disorders and cancer - finding method in madness. Nat Rev Cancer 2015; 15:440-448.

4 Danhier P, Banski P, Payen VL, et al. Cancer metabolism in space and time: beyond the Warburg effect. Biochim Biophys Acta 2017; 1858:556-572.

5 Chen DS, Mellman I. Elements of cancer immunity and the 
cancer-immune set point. Nature 2017; 541:321-330.

6 Galluzzi L, Buque A, Kepp O, Zitvogel L, Kroemer G. Immunological effects of conventional chemotherapy and targeted anticancer agents. Cancer Cell 2015; 28:690-714.

7 Vyas S, Zaganjor E, Haigis MC. Mitochondria and Cancer. Cell 2016; 166:555-566.

8 Wallace DC. Mitochondria and cancer. Nat Rev Cancer 2012; 12:685-698.

9 Soares MP, Teixeira L, Moita LF. Disease tolerance and immunity in host protection against infection. Nat Rev Immunol 2017; 17:83-96.

10 Burgio GR. Commentary on the biological self: toward a "Biological Ego". From Garrod's "chemical individuality" to Burnet's "self". Thymus 1990; 16:99-117.

11 Vander Heiden MG, Cantley LC, Thompson CB. Understanding the Warburg effect: the metabolic requirements of cell proliferation. Science 2009; 324:1029-1033.

12 Warburg O, Wind F, Negelein E. The Metabolism of tumors in the body. J Gen Physiol 1927; 8:519-530.

13 Weinhouse S. On respiratory impairment in cancer cells. Science 1956; 124:267-269.

14 Warburg O. On the origin of cancer cells. Science 1956; 123:309-314.

15 Zamzami N, Marchetti P, Castedo M, et al. Sequential reduction of mitochondrial transmembrane potential and generation of reactive oxygen species in early programmed cell death. J Exp Med 1995; 182:367-377.

16 Zamzami N, Marchetti P, Castedo M, et al. Reduction in mitochondrial potential constitutes an early irreversible step of programmed lymphocyte death in vivo. J Exp Med 1995; 181:1661-1672.

17 Zamzami N, Susin SA, Marchetti P, et al. Mitochondrial control of nuclear apoptosis. J Exp Med 1996; 183:1533-1544.

18 Liu X, Kim CN, Yang J, Jemmerson R, Wang X. Induction of apoptotic program in cell-free extracts: requirement for dATP and cytochrome c. Cell 1996; 86:147-157.

19 Hanahan D, Weinberg RA. The hallmarks of cancer. Cell 2000; 100:57-70.

20 Fulda S, Galluzzi L, Kroemer G. Targeting mitochondria for cancer therapy. Nat Rev Drug Discov 2010; 9:447-464.

21 Ashkenazi A, Fairbrother WJ, Leverson JD, Souers AJ. From basic apoptosis discoveries to advanced selective BCL-2 family inhibitors. Nat Rev Drug Discov 2017; 16:273-284.

22 Dang L, White DW, Gross S, et al. Cancer-associated IDH1 mutations produce 2-hydroxyglutarate. Nature 2009; 462:739-744.

23 Fendt SM, Bell EL, Keibler MA, et al. Reductive glutamine metabolism is a function of the alpha-ketoglutarate to citrate ratio in cells. Nat Commun 2013; 4:2236.

24 Wise DR, Ward PS, Shay JE, et al. Hypoxia promotes isocitrate dehydrogenase-dependent carboxylation of alpha-ketoglutarate to citrate to support cell growth and viability. Proc Natl Acad Sci USA 2011; 108:19611-19616.

25 Martinez-Outschoorn UE, Peiris-Pages M, Pestell RG, Sotgia F, Lisanti MP. Cancer metabolism: a therapeutic perspective. Nat Rev Clin Oncol 2017; 14:11-31.

26 Galluzzi L, Kepp O, Vander Heiden MG, Kroemer G. Metabolic targets for cancer therapy. Nat Rev Drug Discov 2013; 12:829-846.
27 Allison KE, Coomber BL, Bridle BW. Metabolic reprogramming in the tumour microenvironment: a hallmark shared by cancer cells and T lymphocytes. Immunology 2017; 152:175184.

28 Weinberg F, Hamanaka R, Wheaton WW, et al. Mitochondrial metabolism and ROS generation are essential for Kras-mediated tumorigenicity. Proc Natl Acad Sci USA 2010; 107:8788-8793.

29 Zitvogel L, Pitt JM, Daillere R, Smyth MJ, Kroemer G. Mouse models in oncoimmunology. Nat Rev Cancer 2016; 16:759-773.

30 Sabharwal SS, Schumacker PT. Mitochondrial ROS in cancer: initiators, amplifiers or an Achilles' heel? Nat Rev Cancer 2014; 14:709-721.

31 Gaude E, Frezza C. Defects in mitochondrial metabolism and cancer. Cancer Metab 2014; 2:10.

32 Czabotar PE, Lessene G, Strasser A, Adams JM. Control of apoptosis by the BCL-2 protein family: implications for physiology and therapy. Nat Rev Mol Cell Biol 2014; 15:4963.

33 Izzo V, Bravo-San Pedro JM, Sica V, Kroemer G, Galluzzi L. Mitochondrial permeability transition: new findings and persisting uncertainties. Trends Cell Biol 2016; 26:655-667.

34 Sung HJ, Ma W, Starost MF, et al. Ambient oxygen promotes tumorigenesis. PLoS One 2011; 6:e19785.

35 Iommarini L, Ghelli A, Gasparre G, Porcelli AM. Mitochondrial metabolism and energy sensing in tumor progression. Biochim Biophys Acta 2017; 1858:582-590.

36 Galluzzi L, Baehrecke EH, Ballabio A, et al. Molecular definitions of autophagy and related processes. EMBO J 2017; 36:1811-1836.

37 Park SM, Ou J, Chamberlain L, et al. U2AF35(S34F) promotes transformation by directing aberrant ATG7 pre-mRNA $3^{\prime}$ end formation. Mol Cell 2016; 62:479-490.

38 Galluzzi L, Pietrocola F, Bravo-San Pedro JM, et al. Autophagy in malignant transformation and cancer progression. EMBO J 2015; 34:856-880.

39 Rosenfeldt MT, O'Prey J, Morton JP, et al. p53 status determines the role of autophagy in pancreatic tumour development. Nature 2013; 504:296-300.

40 Sumpter R Jr, Sirasanagandla S, Fernandez AF, et al. Fanconi anemia proteins function in mitophagy and immunity. Cell 2016; 165:867-881.

41 Liou GY, Doppler H, DelGiorno KE, et al. Mutant KRas-induced mitochondrial oxidative stress in acinar cells upregulates EGFR signaling to drive formation of pancreatic precancerous lesions. Cell Rep 2016; 14:2325-2336.

42 Sullivan LB, Gui DY, Vander Heiden MG. Altered metabolite levels in cancer: implications for tumour biology and cancer therapy. Nat Rev Cancer 2016; 16:680-693.

43 Xiao M, Yang H, Xu W, et al. Inhibition of alpha-KG-dependent histone and DNA demethylases by fumarate and succinate that are accumulated in mutations of FH and SDH tumor suppressors. Genes Dev 2012; 26:1326-1338.

$44 \mathrm{Xu} \mathrm{W}$, Yang H, Liu Y, et al. Oncometabolite 2-hydroxyglutarate is a competitive inhibitor of alpha-ketoglutarate-dependent dioxygenases. Cancer Cell 2011; 19:17-30.

45 Lu C, Ward PS, Kapoor GS, et al. IDH mutation impairs histone demethylation and results in a block to cell differen- 
tiation. Nature 2012; 483:474-478.

46 Saha SK, Parachoniak CA, Ghanta KS, et al. Mutant IDH inhibits HNF-4alpha to block hepatocyte differentiation and promote biliary cancer. Nature 2014; 513:110-114.

47 Koivunen P, Lee S, Duncan CG, et al. Transformation by the (R)-enantiomer of 2-hydroxyglutarate linked to EGLN activation. Nature 2012; 483:484-488.

48 Kinch L, Grishin NV, Brugarolas J. Succination of Keap1 and activation of Nrf2-dependent antioxidant pathways in FH-deficient papillary renal cell carcinoma type 2. Cancer Cell 2011; 20:418-420.

49 Masgras I, Ciscato F, Brunati AM, et al. Absence of neurofibromin induces an oncogenic metabolic switch via mitochondrial ERK-mediated phosphorylation of the chaperone TRAP1. Cell Rep 2017; 18:659-672.

50 Sciacovelli M, Guzzo G, Morello V, et al. The mitochondrial chaperone TRAP1 promotes neoplastic growth by inhibiting succinate dehydrogenase. Cell Metab 2013; 17:988-999.

51 Sandoval IT, Delacruz RG, Miller BN, et al. A metabolic switch controls intestinal differentiation downstream of Adenomatous polyposis coli (APC). Elife 2017; 6:e22706.

52 Perciavalle RM, Stewart DP, Koss B, et al. Anti-apoptotic MCL-1 localizes to the mitochondrial matrix and couples mitochondrial fusion to respiration. Nat Cell Biol 2012; 14:575583.

53 Alavian KN, Li H, Collis L, et al. Bcl-xL regulates metabolic efficiency of neurons through interaction with the mitochondrial F1FO ATP synthase. Nat Cell Biol 2011; 13:1224-1233.

54 Tsujimoto Y, Finger LR, Yunis J, Nowell PC, Croce CM. Cloning of the chromosome breakpoint of neoplastic B cells with the $\mathrm{t}(14 ; 18)$ chromosome translocation. Science 1984; 226:1097-1099.

55 Serasinghe MN, Wieder SY, Renault TT, et al. Mitochondrial division is requisite to RAS-induced transformation and targeted by oncogenic MAPK pathway inhibitors. Mol Cell 2015; 57:521-536.

56 Kashatus JA, Nascimento A, Myers LJ, et al. Erk2 phosphorylation of Drp1 promotes mitochondrial fission and MAPK-driven tumor growth. Mol Cell 2015; 57:537-551.

57 Xie Q, Wu Q, Horbinski CM, et al. Mitochondrial control by DRP1 in brain tumor initiating cells. Nat Neurosci 2015; 18:501-510.

58 Childs BG, Gluscevic M, Baker DJ, et al. Senescent cells: an emerging target for diseases of ageing. Nat Rev Drug Discov 2017; 16:718-735.

59 Kaplon J, Zheng L, Meissl K, et al. A key role for mitochondrial gatekeeper pyruvate dehydrogenase in oncogene-induced senescence. Nature 2013; 498:109-112.

60 Dong LF, Kovarova J, Bajzikova M, et al. Horizontal transfer of whole mitochondria restores tumorigenic potential in mitochondrial DNA-deficient cancer cells. Elife 2017; 6:e22187.

61 Morais R, Zinkewich-Peotti K, Parent M, et al. Tumor-forming ability in athymic nude mice of human cell lines devoid of mitochondrial DNA. Cancer Res 1994; 54:3889-3896.

62 Tan AS, Baty JW, Dong LF, et al. Mitochondrial genome acquisition restores respiratory function and tumorigenic potential of cancer cells without mitochondrial DNA. Cell Metab 2015; 21:81-94.

63 Rebbeck CA, Leroi AM, Burt A. Mitochondrial capture by a transmissible cancer. Science 2011; 331:303.

64 Guo JY, Karsli-Uzunbas G, Mathew R, et al. Autophagy suppresses progression of K-ras-induced lung tumors to oncocytomas and maintains lipid homeostasis. Genes Dev 2013; 27:1447-1461.

65 Rao S, Tortola L, Perlot T, et al. A dual role for autophagy in a murine model of lung cancer. Nat Commun 2014; 5:3056.

66 Joshi S, Tolkunov D, Aviv H, et al. The genomic landscape of renal oncocytoma identifies a metabolic barrier to tumorigenesis. Cell Rep 2015; 13:1895-1908.

67 King MP, Attardi G. Human cells lacking mtDNA: repopulation with exogenous mitochondria by complementation. Science 1989; 246:500-503.

68 Birsoy K, Wang T, Chen WW, et al. An essential role of the mitochondrial electron transport chain in cell proliferation is to enable aspartate synthesis. Cell 2015; 162:540-551.

69 Sullivan LB, Gui DY, Hosios AM, et al. Supporting aspartate biosynthesis is an essential function of respiration in proliferating cells. Cell 2015; 162:552-563.

70 Shukla SK, Purohit V, Mehla K, et al. MUC1 and HIF-1alpha signaling crosstalk induces anabolic glucose metabolism to impart gemcitabine resistance to pancreatic cancer. Cancer Cell 2017; 32:71-87.e77.

71 Sun RC, Denko NC. Hypoxic regulation of glutamine metabolism through HIF1 and SIAH2 supports lipid synthesis that is necessary for tumor growth. Cell Metab 2014; 19:285-292.

72 Son J, Lyssiotis CA, Ying H, et al. Glutamine supports pancreatic cancer growth through a KRAS-regulated metabolic pathway. Nature 2013; 496:101-105.

73 Metallo CM, Gameiro PA, Bell EL, et al. Reductive glutamine metabolism by IDH1 mediates lipogenesis under hypoxia. Nature 2011; 481:380-384.

74 Altman BJ, Stine ZE, Dang CV. From Krebs to clinic: glutamine metabolism to cancer therapy. Nat Rev Cancer 2016; 16:619-634.

75 Mashimo T, Pichumani K, Vemireddy V, et al. Acetate is a bioenergetic substrate for human glioblastoma and brain metastases. Cell 2014; 159:1603-1614.

76 Jain M, Nilsson R, Sharma S, et al. Metabolite profiling identifies a key role for glycine in rapid cancer cell proliferation. Science 2012; 336:1040-1044.

77 Maddocks OD, Labuschagne CF, Adams PD, Vousden KH. Serine metabolism supports the methionine cycle and DNA/ RNA methylation through de novo ATP synthesis in cancer cells. Mol Cell 2016; 61:210-221.

78 Kennedy KM, Scarbrough PM, Ribeiro A, et al. Catabolism of exogenous lactate reveals it as a legitimate metabolic substrate in breast cancer. PLoS One 2013; 8:e75154.

79 Fan J, Ye J, Kamphorst JJ, et al. Quantitative flux analysis reveals folate-dependent NADPH production. Nature 2014; 510:298-302.

80 Corbet C, Pinto A, Martherus R, et al. Acidosis drives the reprogramming of fatty acid metabolism in cancer cells through changes in mitochondrial and histone acetylation. Cell Metab 2016; 24:311-323.

81 Pietrocola F, Galluzzi L, Bravo-San Pedro JM, Madeo F, Kroemer G. Acetyl coenzyme A: a central metabolite and second messenger. Cell Metab 2015; 21:805-821.

82 Rohrig F, Schulze A. The multifaceted roles of fatty acid 
synthesis in cancer. Nat Rev Cancer 2016; 16:732-749.

83 Wellen KE, Hatzivassiliou G, Sachdeva UM, et al. ATP-citrate lyase links cellular metabolism to histone acetylation. Science 2009; 324:1076-1080.

84 Marino G, Pietrocola F, Eisenberg T, et al. Regulation of autophagy by cytosolic acetyl-coenzyme A. Mol Cell 2014; 53:710-725.

85 Pavlova NN, Thompson CB. The emerging hallmarks of cancer metabolism. Cell Metab 2016; 23:27-47.

86 Zhao S, Torres A, Henry RA, et al. ATP-citrate lyase controls a glucose-to-acetate metabolic switch. Cell Rep 2016; 17:1037-1052.

87 Mullen AR, Wheaton WW, Jin ES, et al. Reductive carboxylation supports growth in tumour cells with defective mitochondria. Nature 2011; 481:385-388.

88 Ye J, Fan J, Venneti S, et al. Serine catabolism regulates mitochondrial redox control during hypoxia. Cancer Discov 2014; 4:1406-1417.

89 Coloff JL, Murphy JP, Braun CR, et al. Differential glutamate metabolism in proliferating and quiescent mammary epithelial cells. Cell Metab 2016; 23:867-880.

90 Dey P, Baddour J, Muller F, et al. Genomic deletion of malic enzyme 2 confers collateral lethality in pancreatic cancer. Nature 2017; 542:119-123.

91 Kang HB, Fan J, Lin R, et al. Metabolic rewiring by oncogenic BRAF V600E links ketogenesis pathway to BRAFMEK1 signaling. Mol Cell 2015; 59:345-358.

92 Xia S, Lin R, Jin L, et al. Prevention of dietary-fat-fueled ketogenesis attenuates BRAF V600E tumor growth. Cell Metab 2017; 25:358-373.

93 Sena LA, Chandel NS. Physiological roles of mitochondrial reactive oxygen species. Mol Cell 2012; 48:158-167.

94 Petros JA, Baumann AK, Ruiz-Pesini E, et al. mtDNA mutations increase tumorigenicity in prostate cancer. Proc Natl Acad Sci USA 2005; 102:719-724.

95 Willems PH, Rossignol R, Dieteren CE, Murphy MP, Koopman WJ. Redox homeostasis and mitochondrial dynamics. Cell Metab 2015; 22:207-218.

96 McGuirk S, Gravel SP, Deblois G, et al. PGC-1alpha supports glutamine metabolism in breast cancer. Cancer Metab 2013; 1:22.

97 Formentini L, Sanchez-Arago M, Sanchez-Cenizo L, Cuezva JM. The mitochondrial ATPase inhibitory factor 1 triggers a ROS-mediated retrograde prosurvival and proliferative response. Mol Cell 2012; 45:731-742.

98 Bonora M, Wieckowski MR, Chinopoulos C, et al. Molecular mechanisms of cell death: central implication of ATP synthase in mitochondrial permeability transition. Oncogene 2015; 34:1475-1486.

99 Dorr JR, Yu Y, Milanovic M, et al. Synthetic lethal metabolic targeting of cellular senescence in cancer therapy. Nature 2013; 501:421-425.

100 Demaria M, O'Leary MN, Chang J, et al. Cellular senescence promotes adverse effects of chemotherapy and cancer relapse. Cancer Discov 2017; 7:165-176.

101 Green DR, Galluzzi L, Kroemer G. Cell biology. Metabolic control of cell death. Science 2014; 345:1250256.

102 Bonnet S, Archer SL, Allalunis-Turner J, et al. A mitochondria- $\mathrm{K}+$ channel axis is suppressed in cancer and its nor- malization promotes apoptosis and inhibits cancer growth. Cancer Cell 2007; 11:37-51.

103 Goldin N, Arzoine L, Heyfets A, et al. Methyl jasmonate binds to and detaches mitochondria-bound hexokinase. Oncogene 2008; 27:4636-4643.

104 Vaughn AE, Deshmukh M. Glucose metabolism inhibits apoptosis in neurons and cancer cells by redox inactivation of cytochrome c. Nat Cell Biol 2008; 10:1477-1483.

105 Jiang L, Shestov AA, Swain P, et al. Reductive carboxylation supports redox homeostasis during anchorage-independent growth. Nature 2016; 532:255-258.

106 DeNicola GM, Karreth FA, Humpton TJ, et al. Oncogene-induced Nrf2 transcription promotes ROS detoxification and tumorigenesis. Nature 2011; 475:106-109.

107 Ruckenstuhl C, Buttner S, Carmona-Gutierrez D, et al. The Warburg effect suppresses oxidative stress induced apoptosis in a yeast model for cancer. PLoS One 2009; 4:e4592.

108 Hausenloy DJ, Yellon DM. Ischaemic conditioning and reperfusion injury. Nat Rev Cardiol 2016; 13:193-209.

109 Ristow M. Unraveling the truth about antioxidants: mitohormesis explains ROS-induced health benefits. Nat Med 2014; 20:709-711.

110 Galluzzi L, Bravo-San Pedro JM, Levine B, Green DR, Kroemer G. Pharmacological modulation of autophagy: therapeutic potential and persisting obstacles. Nat Rev Drug Discov 2017; 16:487-511.

111 Traba J, Del Arco A, Duchen MR, Szabadkai G, Satrustegui J. SCaMC-1 promotes cancer cell survival by desensitizing mitochondrial permeability transition via ATP/ADP-mediated matrix $\mathrm{Ca}(2+)$ buffering. Cell Death Differ 2012; 19:650660.

112 Li J, Huang Q, Long X, et al. Mitochondrial elongation-mediated glucose metabolism reprogramming is essential for tumour cell survival during energy stress. Oncogene 2017; 36:4901-4912.

113 Gomes LC, Di Benedetto G, Scorrano L. During autophagy mitochondria elongate, are spared from degradation and sustain cell viability. Nat Cell Biol 2011; 13:589-598.

114 Hensley CT, Faubert B, Yuan Q, et al. Metabolic heterogeneity in human lung tumors. Cell 2016; 164:681-694.

115 Tabassum DP, Polyak K. Tumorigenesis: it takes a village. Nat Rev Cancer 2015; 15:473-483.

116 McGranahan N, Swanton C. Clonal heterogeneity and tumor evolution: past, present, and the future. Cell 2017; 168:613628.

117 Mayers JR, Torrence ME, Danai LV, et al. Tissue of origin dictates branched-chain amino acid metabolism in mutant Kras-driven cancers. Science 2016; 353:1161-1165.

118 Yuneva MO, Fan TW, Allen TD, et al. The metabolic profile of tumors depends on both the responsible genetic lesion and tissue type. Cell Metab 2012; 15:157-170.

119 Davidson SM, Papagiannakopoulos T, Olenchock BA, et al. Environment impacts the metabolic dependencies of Ras-driven non-small cell lung cancer. Cell Metab 2016; 23:517-528.

120 Peitzsch C, Tyutyunnykova A, Pantel K, Dubrovska A. Cancer stem cells: the root of tumor recurrence and metastases. Semin Cancer Biol 2017; 44:10-24.

121 Palorini R, Votta G, Balestrieri C, et al. Energy metabolism 
characterization of a novel cancer stem cell-like line $3 \mathrm{AB}$ OS. J Cell Biochem 2014; 115:368-379.

122 Shibuya K, Okada M, Suzuki S, et al. Targeting the facilitative glucose transporter GLUT1 inhibits the self-renewal and tumor-initiating capacity of cancer stem cells. Oncotarget 2015; 6:651-661.

123 Ciavardelli D, Rossi C, Barcaroli D, et al. Breast cancer stem cells rely on fermentative glycolysis and are sensitive to 2-deoxyglucose treatment. Cell Death Dis 2014; 5:e1336.

124 Pasto A, Bellio C, Pilotto G, et al. Cancer stem cells from epithelial ovarian cancer patients privilege oxidative phosphorylation, and resist glucose deprivation. Oncotarget 2014; 5:4305-4319.

125 Gammon L, Biddle A, Heywood HK, Johannessen AC, Mackenzie IC. Sub-sets of cancer stem cells differ intrinsically in their patterns of oxygen metabolism. PLoS One 2013; 8:e62493.

126 Mao P, Joshi K, Li J, et al. Mesenchymal glioma stem cells are maintained by activated glycolytic metabolism involving aldehyde dehydrogenase 1A3. Proc Natl Acad Sci USA 2013; 110:8644-8649.

127 Nakajima EC, Van Houten B. Metabolic symbiosis in cancer: refocusing the Warburg lens. Mol Carcinog 2013; 52:329337.

128 Martinez-Outschoorn UE, Pestell RG, Howell A, et al. Energy transfer in "parasitic" cancer metabolism: mitochondria are the powerhouse and Achilles' heel of tumor cells. Cell Cycle 2011; 10:4208-4216.

129 Fiaschi T, Marini A, Giannoni E, et al. Reciprocal metabolic reprogramming through lactate shuttle coordinately influences tumor-stroma interplay. Cancer Res 2012; 72:5130-5140.

130 Sousa CM, Biancur DE, Wang X, et al. Pancreatic stellate cells support tumour metabolism through autophagic alanine secretion. Nature 2016; 536:479-483.

131 Commisso C, Davidson SM, Soydaner-Azeloglu RG, et al. Macropinocytosis of protein is an amino acid supply route in Ras-transformed cells. Nature 2013; 497:633-637.

132 Laurent V, Guerard A, Mazerolles C, et al. Periprostatic adipocytes act as a driving force for prostate cancer progression in obesity. Nat Commun 2016; 7:10230.

133 Nieman KM, Kenny HA, Penicka CV, et al. Adipocytes promote ovarian cancer metastasis and provide energy for rapid tumor growth. Nat Med 2011; 17:1498-1503.

134 Wang YY, Attane C, Milhas D, et al. Mammary adipocytes stimulate breast cancer invasion through metabolic remodeling of tumor cells. JCI Insight 2017; 2:e87489.

135 Wen YA, Xing X, Harris JW, et al. Adipocytes activate mitochondrial fatty acid oxidation and autophagy to promote tumor growth in colon cancer. Cell Death Dis 2017; 8:e2593.

136 Chang CH, Qiu J, O'Sullivan D, et al. Metabolic competition in the tumor microenvironment is a driver of cancer progression. Cell 2015; 162:1229-1241.

137 Ho PC, Bihuniak JD, Macintyre AN, et al. Phosphoenolpyruvate is a metabolic checkpoint of anti-tumor T cell responses. Cell 2015; 162:1217-1228.

138 Uyttenhove C, Pilotte L, Theate I, et al. Evidence for a tumoral immune resistance mechanism based on tryptophan degradation by indoleamine 2,3-dioxygenase. Nat Med 2003; 9:1269-1274.
139 Feron O. Pyruvate into lactate and back: from the Warburg effect to symbiotic energy fuel exchange in cancer cells. $R a-$ diother Oncol 2009; 92:329-333.

140 Sonveaux P, Vegran F, Schroeder T, et al. Targeting lactate-fueled respiration selectively kills hypoxic tumor cells in mice. J Clin Invest 2008; 118:3930-3942.

141 Lopez-Soto A, Gonzalez S, Smyth MJ, Galluzzi L. Control of metastasis by NK cells. Cancer Cell 2017; 32:135-154.

142 Moon DH, Maddahi J, Silverman DH, et al. Accuracy of whole-body fluorine-18-FDG PET for the detection of recurrent or metastatic breast carcinoma. J Nucl Med 1998; 39:431-435.

143 Nieto MA, Huang RY, Jackson RA, Thiery JP. Emt: 2016. Cell 2016; 166:21-45.

144 Frezza C. Mitochondrial metabolites: undercover signalling molecules. Interface Focus 2017; 7:20160100.

145 Sciacovelli M, Goncalves E, Johnson TI, et al. Fumarate is an epigenetic modifier that elicits epithelial-to-mesenchymal transition. Nature 2016; 537:544-547.

146 LeBleu VS, O'Connell JT, Gonzalez Herrera KN, et al. PGC-1alpha mediates mitochondrial biogenesis and oxidative phosphorylation in cancer cells to promote metastasis. Nat Cell Biol 2014; 16:992-1003, 1001-1015.

147 Sun S, Liu J, Zhao M, et al. Loss of the novel mitochondrial protein FAM210B promotes metastasis via PDK4-dependent metabolic reprogramming. Cell Death Dis 2017; 8:e2870.

148 Caino MC, Seo JH, Aguinaldo A, et al. A neuronal network of mitochondrial dynamics regulates metastasis. Nat Commun 2016; 7:13730.

149 Rivadeneira DB, Caino MC, Seo JH, et al. Survivin promotes oxidative phosphorylation, subcellular mitochondrial repositioning, and tumor cell invasion. Sci Signal 2015; 8:ra80.

150 Caino MC, Ghosh JC, Chae YC, et al. PI3K therapy reprograms mitochondrial trafficking to fuel tumor cell invasion. Proc Natl Acad Sci USA 2015; 112:8638-8643.

151 Chourasia AH, Tracy K, Frankenberger C, et al. Mitophagy defects arising from BNip3 loss promote mammary tumor progression to metastasis. EMBO Rep 2015; 16:1145-1163.

152 Ishikawa $\mathrm{K}$, Takenaga $\mathrm{K}$, Akimoto $\mathrm{M}$, et al. ROS-generating mitochondrial DNA mutations can regulate tumor cell metastasis. Science 2008; 320:661-664.

153 Porporato PE, Payen VL, Perez-Escuredo J, et al. A mitochondrial switch promotes tumor metastasis. Cell Rep 2014; 8:754-766.

154 Comito G, Calvani M, Giannoni E, et al. HIF-1alpha stabilization by mitochondrial ROS promotes Met-dependent invasive growth and vasculogenic mimicry in melanoma cells. Free Radic Biol Med 2011; 51:893-904.

155 Park JH, Vithayathil S, Kumar S, et al. Fatty acid oxidation-driven Src links mitochondrial energy reprogramming and oncogenic properties in triple-negative breast cancer. Cell Rep 2016; 14:2154-2165.

156 Gaude E, Frezza C. Tissue-specific and convergent metabolic transformation of cancer correlates with metastatic potential and patient survival. Nat Commun 2016; 7:13041.

$157 \mathrm{Fu} \mathrm{L}$, Dong Q, He J, et al. SIRT4 inhibits malignancy progression of NSCLCs, through mitochondrial dynamics mediated by the ERK-Drp1 pathway. Oncogene 2017; 36:27242736. 
158 Ren T, Zhang H, Wang J, et al. MCU-dependent mitochondrial $\mathrm{Ca} 2+$ inhibits NAD+/SIRT3/SOD2 pathway to promote ROS production and metastasis of HCC cells. Oncogene 2017; 36:5897-5909.

159 Piskounova E, Agathocleous M, Murphy MM, et al. Oxidative stress inhibits distant metastasis by human melanoma cells. Nature 2015; 527:186-191.

160 Le Gal K, Ibrahim MX, Wiel C, et al. Antioxidants can increase melanoma metastasis in mice. Sci Transl Med 2015; 7:308re308.

161 Sayin VI, Ibrahim MX, Larsson E, et al. Antioxidants accelerate lung cancer progression in mice. Sci Transl Med 2014; 6:221ra215.

162 Dupuy F, Tabaries S, Andrzejewski S, et al. PDK1-dependent metabolic reprogramming dictates metastatic potential in breast cancer. Cell Metab 2015; 22:577-589.

163 Galluzzi L, Senovilla L, Vitale I, et al. Molecular mechanisms of cisplatin resistance. Oncogene 2012; 31:1869-1883.

164 Sharma P, Hu-Lieskovan S, Wargo JA, Ribas A. Primary, adaptive, and acquired resistance to cancer immunotherapy. Cell 2017; 168:707-723.

165 Gladstone M, Su TT. Radiation responses and resistance. Int Rev Cell Mol Biol 2012; 299:235-253.

166 Ortiz-Cuaran S, Scheffler M, Plenker D, et al. Heterogeneous mechanisms of primary and acquired resistance to third-generation EGFR inhibitors. Clin Cancer Res 2016; 22:48374847.

167 Conrad M, Angeli JP, Vandenabeele P, Stockwell BR. Regulated necrosis: disease relevance and therapeutic opportunities. Nat Rev Drug Discov 2016; 15:348-366.

168 Galluzzi L, Kepp O, Chan FK, Kroemer G. Necroptosis: mechanisms and relevance to disease. Annu Rev Pathol 2017; 12:103-130.

169 Galluzzi L, Pietrocola F, Levine B, Kroemer G. Metabolic control of autophagy. Cell 2014; 159:1263-1276.

170 Losman JA, Looper RE, Koivunen P, et al. (R)-2-hydroxyglutarate is sufficient to promote leukemogenesis and its effects are reversible. Science 2013; 339:1621-1625.

171 Stein EM, DiNardo CD, Pollyea DA, et al. Enasidenib in mutant IDH2 relapsed or refractory acute myeloid leukemia. Blood 2017; 130:722-731.

172 Trotta AP, Gelles JD, Serasinghe MN, et al. Disruption of mitochondrial electron transport chain function potentiates the pro-apoptotic effects of MAPK inhibition. J Biol Chem 2017; 292:11727-11739.

173 Viale A, Pettazzoni P, Lyssiotis CA, et al. Oncogene ablation-resistant pancreatic cancer cells depend on mitochondrial function. Nature 2014; 514:628-632.

174 Havas KM, Milchevskaya V, Radic K, et al. Metabolic shifts in residual breast cancer drive tumor recurrence. J Clin Invest 2017; 127:2091-2105.

175 Ghosh JC, Siegelin MD, Vaira V, et al. Adaptive mitochondrial reprogramming and resistance to PI3K therapy. $J$ Natl Cancer Inst 2015; 107:dju502.

176 Park S, Chang CY, Safi R, et al. ERRalpha-regulated lactate metabolism contributes to resistance to targeted therapies in breast cancer. Cell Rep 2016; 15:323-335.

177 Vellinga TT, Borovski T, de Boer VC, et al. SIRT1/PGC1alpha-dependent increase in oxidative phosphorylation sup- ports chemotherapy resistance of colon cancer. Clin Cancer Res 2015; 21:2870-2879.

178 Morandi A, Indraccolo S. Linking metabolic reprogramming to therapy resistance in cancer. Biochim Biophys Acta 2017; 1868:1-6.

179 Sancho P, Burgos-Ramos E, Tavera A, et al. MYC/PGC-1alpha balance determines the metabolic phenotype and plasticity of pancreatic cancer stem cells. Cell Metab 2015; 22:590605.

180 Catanzaro D, Gaude E, Orso G, et al. Inhibition of glucose-6-phosphate dehydrogenase sensitizes cisplatin-resistant cells to death. Oncotarget 2015; 6:30102-30114.

181 Gallez B, Neveu MA, Danhier P, Jordan BF. Manipulation of tumor oxygenation and radiosensitivity through modification of cell respiration. A critical review of approaches and imaging biomarkers for therapeutic guidance. Biochim Biophys Acta 2017; 1858:700-711.

182 Jimenez-Valerio G, Martinez-Lozano M, Bassani N, et al. Resistance to antiangiogenic therapies by metabolic symbiosis in renal cell carcinoma PDX models and patients. Cell Rep 2016; 15:1134-1143.

183 Pisarsky L, Bill R, Fagiani E, et al. Targeting metabolic symbiosis to overcome resistance to anti-angiogenic therapy. Cell Rep 2016; 15:1161-1174.

184 Allen E, Mieville P, Warren CM, et al. Metabolic symbiosis enables adaptive resistance to anti-angiogenic therapy that is dependent on mTOR signaling. Cell Rep 2016; 15:11441160 .

185 Catalan E, Charni S, Jaime P, et al. MHC-I modulation due to changes in tumor cell metabolism regulates tumor sensitivity to CTL and NK cells. Oncoimmunology 2015; 4:e985924.

186 Biancur DE, Paulo JA, Malachowska B, et al. Compensatory metabolic networks in pancreatic cancers upon perturbation of glutamine metabolism. Nat Commun 2017; 8:15965.

187 Galluzzi L, Kepp O, Kroemer G. Mitochondria: master regulators of danger signalling. Nat Rev Mol Cell Biol 2012; 13:780-788.

188 Buck MD, Sowell RT, Kaech SM, Pearce EL. Metabolic instruction of immunity. Cell 2017; 169:570-586.

189 Bantug GR, Galluzzi L, Kroemer G, Hess C. The spectrum of T cell metabolism in health and disease. Nat Rev Immunol 2017 Sep 25. doi:10.1038/nri.2017.99.

190 Galluzzi L, Buque A, Kepp O, Zitvogel L, Kroemer G. Immunogenic cell death in cancer and infectious disease. Nat Rev Immunol 2017; 17:97-111.

191 Michaud M, Martins I, Sukkurwala AQ, et al. Autophagy-dependent anticancer immune responses induced by chemotherapeutic agents in mice. Science 2011; 334:1573-1577.

192 Martins I, Wang Y, Michaud M, et al. Molecular mechanisms of ATP secretion during immunogenic cell death. Cell Death Differ 2014; 21:79-91.

193 Ghiringhelli F, Apetoh L, Tesniere A, et al. Activation of the NLRP3 inflammasome in dendritic cells induces IL-1beta-dependent adaptive immunity against tumors. Nat Med 2009; 15:1170-1178.

194 Elliott MR, Chekeni FB, Trampont PC, et al. Nucleotides released by apoptotic cells act as a find-me signal to promote phagocytic clearance. Nature 2009; 461:282-286.

195 Ma Y, Adjemian S, Mattarollo SR, et al. Anticancer chemo- 
therapy-induced intratumoral recruitment and differentiation of antigen-presenting cells. Immunity 2013; 38:729-741.

196 Pietrocola F, Pol J, Vacchelli E, et al. Caloric restriction mimetics enhance anticancer immunosurveillance. Cancer Cell 2016; 30:147-160.

197 Ko A, Kanehisa A, Martins I, et al. Autophagy inhibition radiosensitizes in vitro, yet reduces radioresponses in vivo due to deficient immunogenic signalling. Cell Death Differ 2014; 21:92-99.

198 Saleh AD, Simone BA, Palazzo J, et al. Caloric restriction augments radiation efficacy in breast cancer. Cell Cycle 2013; 12:1955-1963.

199 Simone BA, Dan T, Palagani A, et al. Caloric restriction coupled with radiation decreases metastatic burden in triple negative breast cancer. Cell Cycle 2016; 15:2265-2274.

200 Zhang Q, Raoof M, Chen Y, et al. Circulating mitochondrial DAMPs cause inflammatory responses to injury. Nature 2010; 464:104-107.

201 Vacchelli E, Ma Y, Baracco EE, et al. Chemotherapy-induced antitumor immunity requires formyl peptide receptor 1 . Science 2015; 350:972-978.

202 White MJ, McArthur K, Metcalf D, et al. Apoptotic caspases suppress mtDNA-induced STING-mediated type I IFN production. Cell 2014; 159:1549-1562.

203 Rongvaux A, Jackson R, Harman CC, et al. Apoptotic caspases prevent the induction of type I interferons by mitochondrial DNA. Cell 2014; 159:1563-1577.

204 Sistigu A, Yamazaki T, Vacchelli E, et al. Cancer cell-autonomous contribution of type I interferon signaling to the efficacy of chemotherapy. Nat Med 2014; 20:1301-1309.

205 Vanpouille-Box C, Alard A, Aryankalayil MJ, et al. DNA exonuclease Trex 1 regulates radiotherapy-induced tumour immunogenicity. Nat Commun 2017; 8:15618.

206 Galluzzi L, Lopez-Soto A, Kumar S, Kroemer G. Caspases connect cell-death signaling to organismal homeostasis. Immunity 2016; 44:221-231.

207 Michalek RD, Gerriets VA, Jacobs SR, et al. Cutting edge: distinct glycolytic and lipid oxidative metabolic programs are essential for effector and regulatory CD4+ T cell subsets. J Immunol 2011; 186:3299-3303.

208 Buck MD, O'Sullivan D, Klein Geltink RI, et al. Mitochondrial dynamics controls $\mathrm{T}$ cell fate through metabolic programming. Cell 2016; 166:63-76.

209 Berod L, Friedrich C, Nandan A, et al. De novo fatty acid synthesis controls the fate between regulatory $\mathrm{T}$ and $\mathrm{T}$ helper 17 cells. Nat Med 2014; 20:1327-1333.

210 Sena LA, Li S, Jairaman A, et al. Mitochondria are required for antigen-specific $\mathrm{T}$ cell activation through reactive oxygen species signaling. Immunity 2013; 38:225-236.

211 Weinberg SE, Sena LA, Chandel NS. Mitochondria in the regulation of innate and adaptive immunity. Immunity 2015; 42:406-417.

212 O'Sullivan D, van der Windt GJ, Huang SC, et al. Memory CD8(+) T cells use cell-intrinsic lipolysis to support the metabolic programming necessary for development. Immunity
2014; 41:75-88.

213 Puleston DJ, Zhang H, Powell TJ, et al. Autophagy is a critical regulator of memory $\mathrm{CD} 8(+) \mathrm{T}$ cell formation. Elife 2014; 3:e3706.

214 Angelin A, Gil-de-Gomez L, Dahiya S, et al. Foxp3 reprograms $\mathrm{T}$ cell metabolism to function in low-glucose, high-lactate environments. Cell Metab 2017; 25:1282-1293 e1287.

215 Hossain F, Al-Khami AA, Wyczechowska D, et al. Inhibition of fatty acid oxidation modulates immunosuppressive functions of myeloid-derived suppressor cells and enhances cancer therapies. Cancer Immunol Res 2015; 3:1236-1247.

216 Haschemi A, Kosma P, Gille L, et al. The sedoheptulose kinase CARKL directs macrophage polarization through control of glucose metabolism. Cell Metab 2012; 15:813-826.

217 Jin Z, Wei W, Yang M, Du Y, Wan Y. Mitochondrial complex I activity suppresses inflammation and enhances bone resorption by shifting macrophage-osteoclast polarization. Cell Metab 2014; 20:483-498.

218 Esteban-Martinez L, Sierra-Filardi E, McGreal RS, et al. Programmed mitophagy is essential for the glycolytic switch during cell differentiation. EMBO J 2017; 36:1688-1706.

219 Izquierdo E, Cuevas VD, Fernandez-Arroyo S, et al. Reshaping of human macrophage polarization through modulation of glucose catabolic pathways. J Immunol 2015; 195:24422451 .

220 Wenes M, Shang M, Di Matteo M, et al. Macrophage metabolism controls tumor blood vessel morphogenesis and metastasis. Cell Metab 2016; 24:701-715.

221 Tan HY, Wang N, Li S, et al. The reactive oxygen species in macrophage polarization: reflecting its dual role in progression and treatment of human diseases. Oxid Med Cell Longev 2016; 2016:2795090.

222 Mills EL, Kelly B, Logan A, et al. Succinate dehydrogenase supports metabolic repurposing of mitochondria to drive inflammatory macrophages. Cell 2016; 167:457-470.e13.

223 Zitvogel L, Kepp O, Galluzzi L, Kroemer G. Inflammasomes in carcinogenesis and anticancer immune responses. Nat Immunol 2012; 13:343-351.

224 Galluzzi L, Bravo-San Pedro JM, Demaria S, Formenti SC, Kroemer G. Activating autophagy to potentiate immunogenic chemotherapy and radiation therapy. Nat Rev Clin Oncol 2017; 14:247-258.

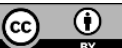

This work is licensed under a Creative Commons Attribution 4.0 Unported License. The images or other third party material in this article are included in the article's Creative Commons license, unless indicated otherwise in the credit line; if the material is not included under the Creative Commons license, users will need to obtain permission from the license holder to reproduce the material. To view a copy of this license, visit http:// creativecommons.org/licenses/by/4.0/

(c) The Author(s) 2017 